\title{
Behaviour Modification for Stigma Reduction and Psychological Functioning Among People Living With HIV/AIDS
}

\author{
Matthew O. Olasupo ${ }^{1}$, Mantwa W. Modiba ${ }^{1} \&$ Erhabor S. Idemudia ${ }^{1}$ \\ ${ }^{1}$ Faculty of Humanities, North-West University (Mafikeng Campus), South Africa \\ Correspondence: Matthew O. Olasupo (PhD), Department of Psychology, Obafemi Awolowo University, Ile-Ife, \\ Nigeria. Tel: 234-803-777-9359. E-mail: gbenga.olasupo@oauife.edu.ng
}

Received: July 31, 2019 Accepted: August 27, 2019 Online Published: September 17, 2019

doi:10.5539/gjhs.v11n11p129 URL: https://doi.org/10.5539/gjhs.v11n11p129

\begin{abstract}
HIV/AIDS stigma is still pervasive and continues to negatively impact the psychological functioning of PLWHA in South African communities. The aim of this study was to design, implement, and to empirically evaluate the efficacy of an HIV/AIDS stigma reduction intervention. Adopting a two-phase study approach, the study was anchored on a cross-sectional design for phase I, and a pre-test post-test control group design for phase II. Phase I study was a baseline assessment of HIV and AIDS stigma experiences as well as psychological functioning among PLWHA, while phase II focused on empirically tailoring an HIV/AIDS stigma reduction intervention - the Stigma Coping Skills Intervention (SCSI). The HIV/AIDS stigma scale was used to determine HIV/AIDS stigma, while the GHQ-28 was used to determine psychological functioning. The sample comprised of 300 PLWHA. Purposive sampling method was employed for phase I study. Phase II study comprised a total of 24 participants equally assigned to experimental and control groups. Simple random sampling method was used for the phase II study. Findings indicated that the intervention was significant on stigma, and was also significant on psychological functioning. The SCSI demonstrated efficacy in HIV and AIDS stigma reduction, as well as improving psychological functioning.
\end{abstract}

Keywords: HIV/AIDS stigma, PLWHA, Psychological functioning, SCSI

\section{Introduction}

HIV/AIDS stigma is widespread, experienced in almost every country and region of the world (Senyalo, Maja, \& Ramukumba, 2015; Yu, Zhang, \& Chan, 2016). The efforts to fight the spread of the pandemic are stalled by persistent stigma (Brent, 2016) and its harmful psychological effects on those living with the virus (Niu, Luo, Liu, Silenzio, \& Xiao, 2016). In HIV/AIDS care, stigma is the most frequently reported problem (Brent, 2016; Niu et al., 2016). The prevalence of psychological dysfunctions in PLWHA is pervasive (Brandt, Zvolensky, Woods, Gonzalez, Safren, \& O'Cleirigh, 2017; Chambers, Rueda, Baker, Wilson, Deutsch, Raeifar et al., 2015) and highly associated with HIV and AIDS stigma (Yi, Chhoun, Suong, Thin, Brody, \& Tuot, 2015; Yu et al., 2016). Research indicates that when HIV and AIDS stigma persists, the hostile living environment erodes PLWHA's coping mechanisms over time, resulting in reduced capacity for coping with new stressors precipitating even poorer psychological functioning (Bogart, Wagner, Galvan, Landrine, \& Klein, 2011). Owing to poor psychological functioning, PLWHA's ability to effectively adhere to treatment gets compromised, hampering efforts to employ treatment as prevention to curb the scourge of the pandemic. Due to poor compliance with HIV treatment, psychological dysfunctions are as a result responsible for morbidity and mortality among this population (Uthman, Magidson, Safren, \& Nachega, 2014). Hence, stigma and psychological dysfunctions remain major problems for PLWHA.

Despite awareness of the negative impact of stigma on the psychological functioning of PLWHA, little has been done thus far to alleviate this problem. Most HIV and AIDS stigma reduction interventions were carried out in non-South African contexts, and most are limited to the exploration of HIV and AIDS stigma (Demmer, 2011; dos Santos, Kruger, Mellors, Wolvaardt, \& van der Ryst, 2014; Maughan-Brown, 2010; Senyalo, Maja, \& Ramukumba, 2015) and its influence on psychological functioning (Idemudia \& Matemela, 2012), and do not have an intervention component to address the status quo. For the few available studies, research indicates that very little is known about the effectiveness of the interventions, and few have demonstrated efficacy (Sikkema, Dennis, Watt, Choil, Yemeke, \& Joska, 2015). Thus, the need for effective HIV stigma and psychological dysfunctions reduction interventions for PLWHA can therefore not be over-emphasized. 
In the absence of interventions that address the stigmatisation of PLWHA in the South African context, these people will continue suffering from psychological problems. The current study, therefore, seeks to design, implement HIV/AIDS stigma and psychological dysfunctions reduction intervention programme; and to empirically evaluate the efficacy of the designed intervention in reducing stigma experiences and psychological dysfunctions among PLWHA.

\subsection{Rationale of the Study}

The rationale of this study was to determine stigma experiences and psychological functioning among PLWHA, in order to design an intervention programme to address such issues, for better psychological functioning of PLWHA and consequently better management of the pandemic.

\section{Phase 1}

\section{Method}

\subsection{Research Design}

Phase I entailed baseline assessment, i.e., determination of participants' stigma experiences and psychological functioning, and cross-sectional research approach was employed.

\subsection{Participants and Sampling Technique}

Phase I study consisted of 300 PLWHA. Due to the nature of participants as hard to find, the purposive sampling method was used. The demographic characteristics of participants are presented in table 1 below. The study was carried out in the Capricorn District of Limpopo Province which is situated in the northern part of South Africa. Capricorn district was chosen for the study because it constitutes a wide variety of racial groups as well as diverse socio-economic levels (Statistics South Africa, 2013). This is subsequent to the economic migration to the district. Participants were recruited from the HIV and AIDS outpatient clinic at Polokwane/Mankweng Hospital Complex (the largest hospital in the province), Rethabile Health Centre, and Takalani Nana HIV Centre in Polokwane. The demographic characteristics of participants are presented in Table 1.

Table 1. Demographic characteristics of phase I participants

\begin{tabular}{lc}
\hline Variables & PLWHA (N=300) \\
\hline Age range & $20-54$ yrs \\
Mean Age & 31 (SD 8.2) \\
\hline Gender & \\
Male & $125(41.5 \%)$ \\
Female & $172(57.1 \%)$ \\
Missing value & $3(1.4 \%)$ \\
\hline Marital Status & \\
Married & $89(29.6 \%)$ \\
Never married & $169(56.1 \%)$ \\
Divorced & $6(2.0 \%)$ \\
Widowed & $18(6.0 \%)$ \\
Missing value & $18(6.3 \%)$ \\
\hline Educational Level & \\
Less than grade 12 & $35(11.6 \%)$ \\
Grade 12 & $76(25.2 \%)$ \\
Tertiary education & $164(54.5 \%)$ \\
Missing value, & $25(9.5 \%)$ \\
\hline
\end{tabular}




$\begin{array}{lc}\text { Duration of Diagnosis (DD) } & \\ \text { Less than } 1 \text { year } & 143(47.5) \\ 2-4 \text { years } & 139(46.5) \\ \text { More than } 5 \text { years } & 18(6.0) \\ \text { Grade } 12 & 76(25.2 \%)\end{array}$

\subsection{Research Instruments}

HIV/AIDS stigma was determined using the perceived stigma of HIV/AIDS scale developed by Westbrook and Bauman (1996) while psychological functioning was assessed using the General Health Questionnaire-28 (GHQ-28) developed by Goldberg (1972). The perceived stigma of HIV/AIDS scale has 47 items with three subscales (internalised stigma, perceived stigma, and enacted stigma) and a global score. Internalised stigma has 20 items of which the participants had to respond on a four-point Likert scale, with 1 indicating strongly agree, and 4 strongly disagree. For internalised stigma the following items were reversed: Items 10, 12, 17, 18, 19, 25, 26. For perceived stigma, there were 18 items of which participants had to respond on a four-point Likert scale, with 1 indicating strongly agree, and 4 strongly disagree. The reversed items in perceived stigma subscale were: Items 30 , $32,37,38,39,45$. For enacted stigma, there were 9 items of which participants had to respond on a three-point Likert scale with 1 = No experience, 2 = Experience, $3=\mathrm{A}$ lot of experience. No reverse scoring was required. In this study scores above the mean score of 99.1 were indicative of high stigma experience. The scale had been adapted and previously applied to the South African population (Idemudia \& Matamela, 2012), and was found to be reliable with a Cronbach's $\alpha=0.88$. For the current study, the scale was found reliable with a Cronbach's $\alpha$ of 0.76 .

The GHQ-28 developed by Goldberg (1972) was adapted (Cronbach's $\alpha=0.92$ ) and used to assess the participants' psychological functioning. The scale was used to establish psychological symptoms experienced by an individual in the past few weeks. The participants had to respond on a four-point Likert scale with $1=$ better than usual, $2=$ same as usual, 3 = worse than usual, $4=$ much worse than usual. The use of the scoring method ' $0-0-1-1$ ' was suggested by Goldberg to assist reduce biases resulting from participants who tend to choose responses 0 and 3 or 1 and 2. The higher the score, the poorer the psychological functioning of the participant. The scale consists of 28 items that, through factor analysis, have been divided into four sub-scales, which are as follows: A - Somatic symptoms (items 1-7), B - Anxiety/insomnia (items 8-14), C - Social dysfunction (items 15-21), and D - Severe depression (items 22-28). Participants' global score was used in this study and anyone who scored higher than the mean score of 67.24 was considered high in psychological dysfunctions. The scale had been adapted and used among the South African population (Idemudia \& Matamela, 2012) in their study among HIV/AIDS and cancer patients, and was found to be reliable (Cronbach's $\alpha=0.90$ ).

\subsection{Procedure and Ethical Considerations}

The study was carried out after approval and permission were granted by the North-West University (NWU-00130-11-A9), and the North West Provincial Department of Health Ethics committees (Ref: 4/2/2). The provincial approval letter was used to gain access to the institutions where data were collected. Eligibility criteria of the study were: being diagnosed with HIV (on self-report), and be at least 18 years of age or older to be able to give or considered competent to give informed consent. Those who appeared too ill, the mentally unstable or mentally disabled or who had any other condition that would impair their ability to consent were excluded. Participation in the study was voluntary. The right not to participate, as well as to withdraw from the study at any point was outlined. Formal informed consent was obtained from individuals who volunteered to partake in the study.

\subsection{Data Analysis}

Descriptive statistics were used to determine the mean score for PLWHA who are high in stigma experiences and psychological dysfunctions. Participants who scored higher than the mean score on the stigma scale were considered stigmatised and those that scored higher than the mean score on the psychological functioning scale were also categorised as dysfunctional and isolated for the phase II (intervention) of the study. 


\section{Results}

Table 2. Means and Standard deviation of stigma dimensions and psychological functioning among PLWHA at baseline

\begin{tabular}{llc}
\hline Variable & PLWHA (N=300) & \\
\hline & $x$ & $\sigma$ \\
\hline stigma & 99.1 & 3.57 \\
Psychological functioning & 67.24 & 11.34 \\
\hline
\end{tabular}

The result indicated that 253 PLWHA $(\mathrm{N}=300)$ scored above the mean score of 99.1 on stigma while 228 PLWHA $(\mathrm{N}=300)$ scored above the mean score of 67.24 on psychological dysfunctions. Hence, 24 PLWHA who were high on stigma and psychological dysfunctions were randomly selected for the phase II study.

\section{Phase 2}

\section{Method}

\subsection{Research Design}

For phase II, the pre-test-post-test control group design was used, as depicted in Figure 1 below. The pre-test-post-test design is a commonly employed design in behavioural research. It is mainly used to compare groups and/or assess change resulting from intervention programmes. The design involves randomly assigning participants with similar experiences to either the experimental or control group, and administer the pre-test to both groups. The experimental group is then exposed to an intervention programme, while the control group does not get exposed.

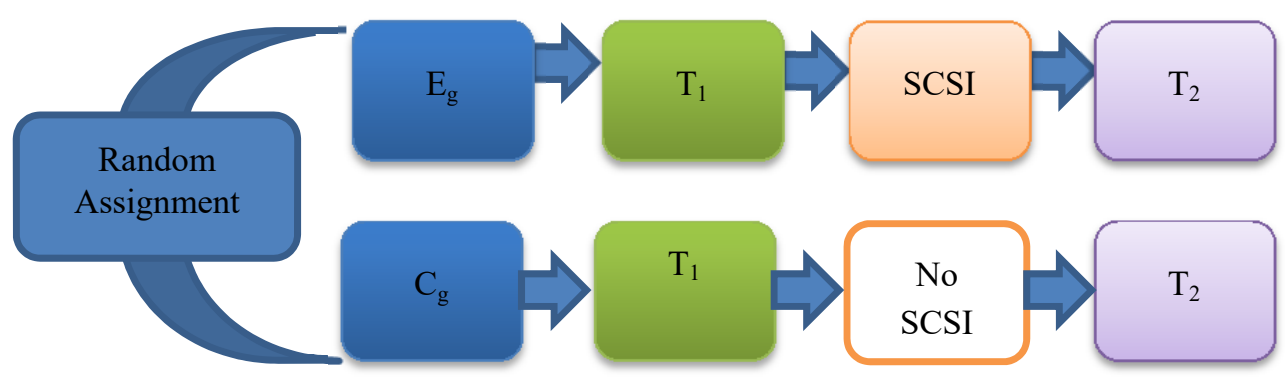

Eg. $=$ Experimental group, $\mathrm{Cg}=$ Control group, $\mathrm{T}_{1}=$ Pre-test, $\mathrm{SCSI}=$ Stigma Coping Skills Intervention, $\mathrm{T}_{2}=$ Post-test

Figure 1. Pre-test-post-test control group design

\subsection{Participants and Sampling Technique}

The study consisted of 24 participants who were found to report stigma experiences and psychological dysfunctions at baseline assessment in phase I. Twelve participants (12) were assigned to the experimental and 12 to the control group. The demographic information of participants in phase II is presented in Table III below. Simple random sampling was done to select participants from the baseline data for phase II. Participants whose questionnaires were sampled were contacted and invited for the intervention. They were all willing to continue into the phase II study after being told that the intervention programme will assist them in their recovery process. 
Table 3. Demographic characteristics for phase II participants

\begin{tabular}{lll}
\hline & Experimental (N = 12) & Control (N = 12) \\
\hline $\begin{array}{l}\text { Age range } \\
\text { Mean Age }\end{array}$ & $20-35$ yrs & $20-35$ yrs \\
Gender & $28(\mathrm{SD} 3.10)$ & $31(\mathrm{SD} 8.2)$ \\
$\quad$ Male & $5(41.7 \%)$ & $7(58.3 \%)$ \\
$\quad$ Female & $7(58.3 \%)$ & $5(41.7 \%)$ \\
Marital Status & & \\
$\quad$ Married & $2(16.7 \%)$ & $4(33.3 \%)$ \\
$\quad$ Never married & $10(83.3 \%)$ & $7(58.3 \%)$ \\
$\quad$ Divorced & $0(0.0 \%)$ & $0(0.0 \%)$ \\
$\quad$ Widowed & $0(0.0 \%)$ & $1(8.3 \%)$ \\
Educational Level & & $2(16.7 \%)$ \\
$\quad$ Less than grade 12 & $3(25.0 \%)$ & $2(16.7 \%)$ \\
Grade 12 & $3(25.0 \%)$ & $4(33.3 \%)$ \\
Tertiary education & $6(50.0 \%)$ & \\
Duration of Diagnosis(DD) & & $6(50.0 \%)$ \\
Less than 1 year & $9(75 \%)$ & $5(41.7 \%)$ \\
2-4 years & $3(25 \%)$ & $\mathbf{1 ( 8 . 3 \% )}$ \\
More than 5 years & $\mathbf{0 ( 0 \% )}$ &
\end{tabular}

\subsection{Procedure}

Results of the baseline assessment informed the development of the intervention programme in accordance with variables under investigation. The participants who reported experiences of stigma and psychological dysfunction at baseline were the ones targeted for the intervention. A Theory-based therapeutic approach was used by a qualified practitioner (clinical psychologist) to provide and facilitate the intervention. To ensure objectivity, participants were seen under a uniform condition and given uniform treatment. The participants were seen once a week for eight weeks, with an intervention programme for each week clearly outlined. After the intervention programme was completed, post-test was conducted to assess the effect of the intervention programme on HIV/AIDS stigma and psychological dysfunction.

\subsection{Instruments}

The perceived stigma of HIV/AIDS scale and the GHQ 28 that were used in phase I study were used again in phase II for the post-test to establish the efficacy of the SCSI programme in alleviating stigma and improve psychological functioning. The instrument's psychometric properties have already been outlined in the phase I study.

\subsection{Assessment}

The assessment was conducted at pre- and post-test in an eight-week intervention programme. The same instruments, i.e., HIV and AIDS stigma scale and the GHQ 28 that were used at pre-test were also used at post-test.

\subsection{Experimental Conditions}

Participants were seen once a week for eight weeks, with an intervention programme for each week clearly outlined. The duration of each session was 60-90 minutes. After the intervention programme was completed, post-test was conducted to assess the effect of the intervention programme on HIV and AIDS stigma and psychological dysfunctions. Participants were exposed to uniform experimental conditions.

\subsection{The Group Process (The Stigma Coping Skills Intervention-SCSI)}

A Theory-based therapeutic approach was used by a qualified clinical psychologist registered with the Health Professions Council of South Africa (HPCSA), to provide and facilitate the intervention programme. The group process of the SCSI programme was conducted in accordance with Yalom's group therapy approach (Yalom, 1995). 
The SCSI was both a time-limited, usually run between eight and ten sessions (Yalom, 1995) and focused therapy group. Focused therapy group is a group that is centred on a specific topic or problem area that all group members have, that is, it focuses on a homogeneous problem. Hence, the present study entailed only PLWHA with experiences of stigma and psychological dysfunctions. Focused therapy groups are also skilled development groups, assisting members learn adaptive coping skills and/or changing maladaptive behaviour. The intervention was time-limited group, it had the beginning, middle and end, and did not add new members after the first few sessions had started. The intervention was anchored on the CBT (Cognitive Behavioural Therapy). The SCSI process is outlined below:

\subsection{Session 1: Group Formation}

During group formation, pre-group preparation was done for the smooth running of the group which involved paying attention to early group discomfort, encouraging member-to-member interaction, and modelling appropriate behaviour for solid foundation laying. This is the session during which clear goals were set: setting group norms, setting basic group ground rules such as respect for each other, encouraging participation and taking care of participants' own needs. An outline of ethical aspects to be observed was made with special emphasis on confidentiality. This was done to promote trust, openness and loyalty to the group. Rapport with participants was established. Ice-breakers were used to make participants feel at ease. The participants were given the chance to know each other by introducing themselves to members of the group. Introduction of the purpose of the group was done by the facilitator, who is the researcher. The selection criteria for the intervention programme was outlined. An outline of the course of the intervention programme was made as well in this session to make participants aware of the nature of the programme and aspects to expect in subsequent sessions.

\subsection{Session 2: Identification of Stressors and Coping Mechanisms}

In this session, participants were afforded an opportunity to freely relate and vent out their personal stressors and experiences in a safe and supportive environment in relation to HIV and AIDS stigma. As was indicated earlier on that the intervention was informed by the results of the baseline assessment, baseline results showed that PLWHA experienced HIV and AIDS stigma from all dimensions (i.e., internalised, perceived and enacted HIV/AIDS stigma), but enacted HIV/AIDS stigma was significantly more experienced relative to other stigma dimensions. As a result, the intervention comprised all the stigma dimensions, although the emphasis was put more on the enacted stigma. Participants' feelings were acknowledged and normalised with unconditional positive regard. Those who became emotionally distressed as they related their experiences were contained. The participants were also given a chance to relate and share coping strategies they use to deal with their stigma experiences. Maladaptive coping skills by group members were noted, such as avoidance or disengagement.

\subsection{Session 3: HIV and AIDS Knowledge (Information Empowerment)}

Review of the participants' basic HIV/AIDS knowledge was done to establish their level of knowledge, so as to equip them with adequate information. The following were some of the questions that were asked to determine participants' basic knowledge base:

\section{- HIV/AIDS Basic Information:}

$>$ What is HIV?

$>$ What is AIDS?

$>$ Are HIV and AIDS the same thing?

\section{- Transmission Mode}

Will a person get HIV by doing the following?

$>$ Hugging an HIV positive person.

$>$ Shaking hands with an HIV positive person.

$>$ Sharing a glass of water with an HIV positive person.

> Sharing a toilet with an HIV positive person.

$>$ Eating from the same plate with an HIV positive person.

$>$ Sharing a bed with an HIV positive person.

$>$ Semen and vaginal fluids during sexual intercourse.

$>$ Contact with infected blood. 
$>$ Blood transfusion.

The facilitator conducted the discussion of the questions in an interactive manner during group session, and thereafter psycho-education on HIV/AIDS basic information including transmission modes was provided by the facilitator.

\subsection{Session 4: Communication Skills (Skills Empowerment)}

The participants were empowered with healthy and effective communication skills which included role-plays as well as take-home practice tasks. The take-home tasks required them to apply the skills learnt in stigmatising situations they encounter in their respective settings, to alleviate the distress that usually arises from maladaptive communication patterns.

\subsection{Session 5: Assertive Skills - (Skills Empowerment)}

The participants were equipped with assertive skills so as to enable them to assert themselves to prevent distress in stigmatising situations. This included equipping them with skills to stand their ground without being arrogant, learn under which circumstances they need to be assertive, learn differences between assertiveness and arrogance. Assertive training also included role-plays among the group members, as well as take-home tasks to exercise the skills learnt.

\subsection{Session 6: Cognitive Restructuring (Psychotherapeutic) - CBT orientated}

Psychological interventions aimed at dealing with depression and anxiety among PLWHA that have a cognitive behavioural dimension have been found to be effective (Sherr, Clucas, Harding, Sibley, \& Catalan, 2011), hence the CBT was the psychotherapeutic approach of choice for the intervention programme of the present study. During the intervention, HIV and AIDS stigma was tackled as per its dimensions, for example:

- Internalised HIV and AIDS stigma: Individuals who are stigmatised tend to internalise the tarnished mark or label (e.g. sexually immoral) imposed upon them by the stigmatisers (Goffman, 1963), resulting in internalised stigma. This often manifests in the form of self-defeating thoughts and self-blame predisposing them to psychological dysfunction. As a result, the self-defeating, and irrational thoughts that lead to internalisation of stigma were challenged and disputed.

- Perceived HIV and AIDS stigma: Due to the knowledge that PLWHA are perceived negatively and as a result are avoided, this knowledge, therefore, precipitated perceived stigma among PLWHA. Mind-reading cognitive distortions that lead to stigma anticipation and perception were also challenged and disputed.

- Enacted HIV and AIDS stigma: Reframing, providing alternative interpretations of stigma enactments was done to reduce and avoid distress.

- An example of an alternative interpretation was to perceive stigma enactments as an indication of lack of knowledge and a call for more HIV and AIDS education. Henceforth the group mutually came up with a motto to assist them to cognitively cope with stigmatising enactments. The motto was: "I don't have a problem, with my status, if you have, it is your problem".

4.14 Session 7: Stress management - (Information Empowerment)

As it is well documented in research that stigmatising attitudes elicit stress to the sufferer (Rael \& Hampanda, 2016), psycho-education on healthy and adaptive stress management strategies were provided in this session. The following were quick-to-use stress-busting strategies that participants were equipped with:

$>$ Speak up; don't bottle up your feelings.

$>$ Don't allow petty things to upset you (mind readings e.g. when people are laughing while you are approaching, don't assume they are laughing at you).

$>$ Hobbies and distractions (do something that interests you).

$>$ A daily dose of humour and laughter is excellent in combatting stress.

Dxercise (contextualised, considering participants socio-economic background).

$>$ Have enough rest/sleep.

\subsection{Session 8: Closure/Termination}

This session involved recapping of aspects and skills learnt in preceding sessions and wrapping up the programme. The participants were given a chance to bid each other farewell. Words of encouragement and well wishes in the 
fight against stigma were given by the group.

A post-test was then administered, using the same instrument that was used during the pre-test. The control group was also exposed to the intervention after they had completed the post-test so that they can equally benefit.

\subsection{Data Analysis}

Paired sample t-test was used to compare experimental and control group differences and Analysis of Covariance (ANCOVA) was used to determine the effect of the SCSI programme on HIV/AIDS stigma and psychological functioning.

\section{Results}

Table 4. Effects of Intervention on the experimental group by stigma dimensions and psychological functioning

\begin{tabular}{|c|c|c|c|c|c|c|}
\hline \multirow[t]{2}{*}{ Variables } & \multicolumn{2}{|c|}{ Pre-test } & \multicolumn{2}{|c|}{ Post-test } & \multirow[b]{2}{*}{$\mathbf{t}$} & \multirow[b]{2}{*}{$p$} \\
\hline & $\mathbf{M}$ & SD & $\mathbf{M}$ & SD & & \\
\hline Stigma & 82.54 & 2.23 & 55.83 & 11.61 & 4.39 & $.00 * *$ \\
\hline Psychological functioning & 77.58 & 10.48 & 28.42 & .99 & -16.15 & $.00 * *$ \\
\hline
\end{tabular}

$* * \mathrm{P}<.001$.

The results indicated that the intervention was significant on stigma when pre-and post-intervention scores were considered. The intervention was also significant for the overall psychological functioning. The pre- and post-intervention scores were significantly different $(\mathrm{p}<0.001)$ for stigma, and psychological functioning, as shown in Table IV above.

The ANCOVA was run to determine the effect of the SCSI on HIV/AIDS stigma (see Table $4 \&$ Graph 1 below). The results revealed the group was statistically significant with regard to stigma post-intervention. That is, the type of group (intervention or control) participants belonged to had an effect on stigma post-intervention $(\mathrm{p}<0.001)$.

Table 5. Covariates of post-intervention on internalised and enacted stigma

\begin{tabular}{lllllll}
\hline Source & SS & DF & MS & F & $\boldsymbol{P}$ & N $p$ \\
\hline Corrected Model & 126.12 & 2 & 63.032 & 191.988 & .000 & .948 \\
Intercept & 224.348 & 1 & 224.348 & 683.337 & .000 & .970 \\
Stigma & .022 & 1 & .022 & .067 & .798 & .003 \\
Group & 120.930 & 1 & 120.930 & 368.340 & .000 & .946 \\
Error & 6.895 & 21 & .328 & & & \\
Total & 3193.000 & 24 & & & & \\
\hline
\end{tabular}




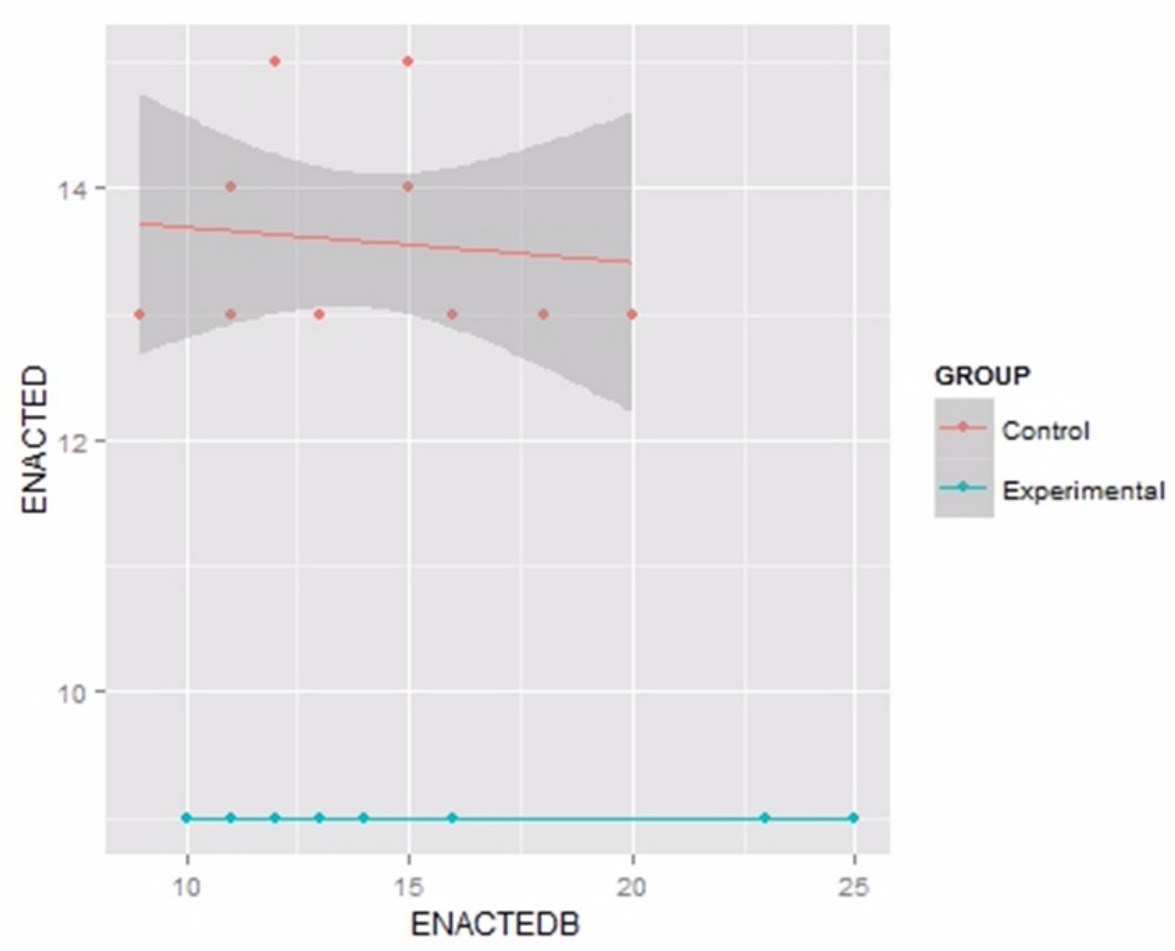

Graph I. Distribution of enacted HIV/AIDS stigma at pre-and post-intervention

ENACTED $=$ Enacted HIV/AIDS stigma at baseline (pre-intervention), ENACTED = Enacted HIV/AIDS stigma post-intervention

The effect of the SCSI on the psychological functioning is depicted on Table 6 and Graph 2 below. Psychological dysfunction reflected by the psychological functioning post-intervention among the experimental group was significantly lower compared with the control group. This shows the SCSI programme was very effective in reducing psychological dysfunction.

Table 6. Covariates of post-intervention psychological functioning

\begin{tabular}{lllllll}
\hline Source & SS & DF & MS & F & P & np \\
\hline Corrected Model & 13586.436 & 2 & 6793.218 & 257.727 & .000 & .961 \\
Intercept & 946.376 & 1 & 946.376 & 35.904 & .000 & .631 \\
GHQ B & 1.394 & 1 & 1.394 & .053 & .820 & .003 \\
Group & 13558.104 & 1 & 13558.104 & 514.379 & .000 & .961 \\
Error & 54.937 & 21 & 2.616 & & & \\
Total & 5171.000 & 24 & & & & \\
\hline
\end{tabular}




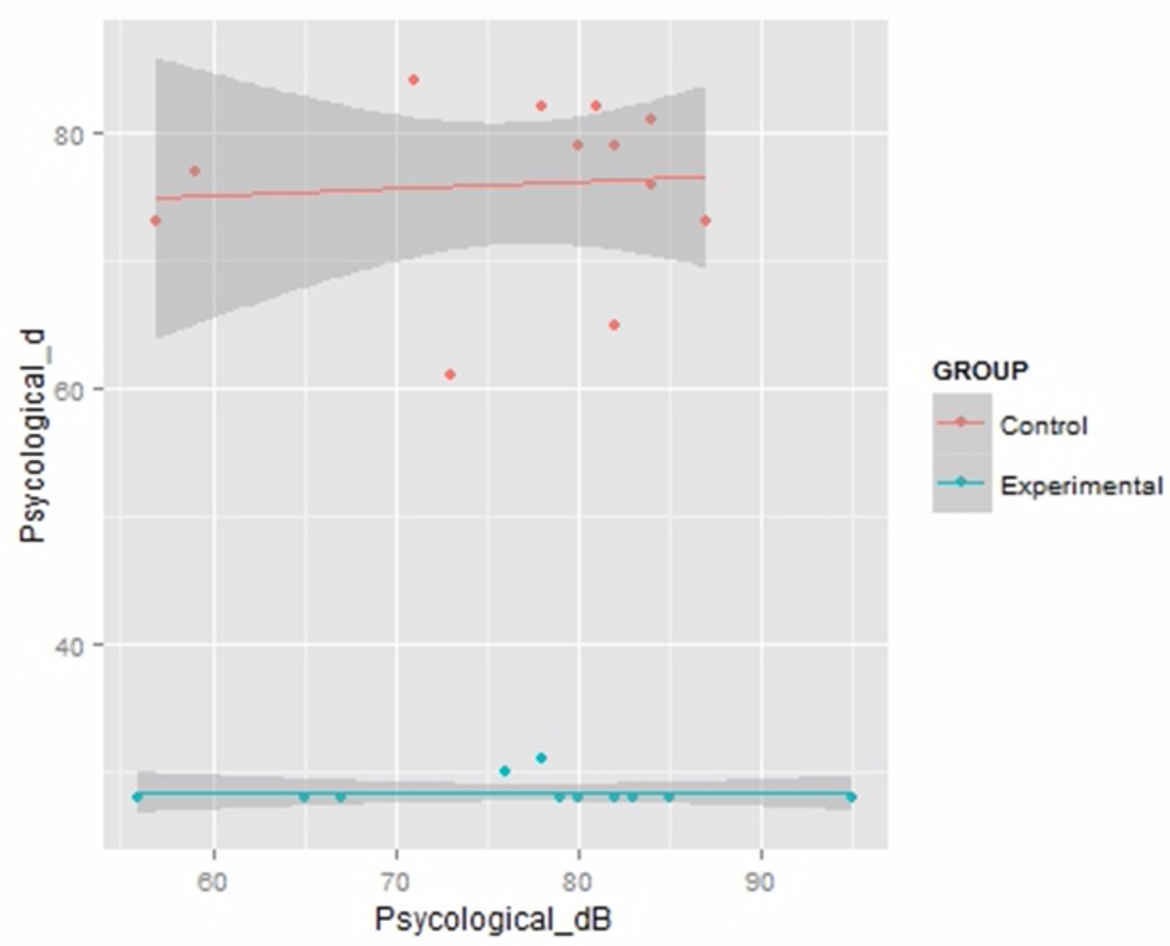

Graph II. Distribution of GHQ at pre- and post-intervention

Psychological_dB $=\mathrm{GHQ}$ at baseline (pre intervention), Psychological_d = GHQ at post intervention.

\section{Discussion}

Post the SCSI intervention, the assessment indicated a statistically significant difference between HIV and AIDS stigma experiences and psychological dysfunction, i.e., at post-test, the experimental group (intervention exposed) reported reduced stigma and diminished psychological dysfunctions. This finding confirms the effectiveness of the SCSI intervention programme in reducing HIV and AIDS stigma and enhancing psychological functioning. The SCSI significantly demonstrated its effectiveness as well in reducing psychological dysfunctions of the participants. High levels of depression, anxiety and social dysfunction among PLWHA significantly diminished following the SCSI programme.

This effectiveness may be attributed to the thoroughness of the needs assessment and the theory-based approach upon which the intervention rest. Boss, Schaalma and Pryor (2008) had earlier speculated that HIV/AIDS-related stigma and psychological dysfunction interventions will most likely be effective if the intervention programmes are based upon thorough needs assessment, theory-and-evidence based strategies and collaborative planning. The involvement of a practising clinical psychologist and the assistance of the nurses on duty might also have contributed to the effectiveness of this intervention (Uys, Chirwa, Kohi, Greeff, Naidoo, Makoae et al., 2009).

\section{Conclusion}

This study has contributed to the literature by adding to the previously developed intervention methods for HIV/AIDS-related stigma and psychological dysfunctions, especially in South Africa. The SCSI is effective in the reduction of HIV and AIDS stigma, as well as psychological dysfunction. The SCSI was found to be effective in empowering participants with efficient skills to deal with HIV and AIDS stigmatising enactments, and in enhancing psychological functioning.

\subsection{Implications for Future Research}

Since the SCIS has proven effective in stigma and psychological dysfunctions reduction, it can, therefore, be replicated and or developed further for use in other contexts, especially because of the scarcity of this kind of interventions in South Africa. 


\section{Competing Interests Statement}

The authors declare that there are no competing or potential conflicts of interest.

\section{References}

Bogart, L. M., Wagner, G. J., Galvan, F. H., Landrine, H., \& Klein, D. J. (2011). Perceived discrimination and mental health symptoms among black men with HIV. Cultural Diversity \& Ethnic Minority Psychology, 1, 295-302. https://doi.org/10.1037/a0024056

Boss, A. E. R., Schaalma, H. P., \& Pryor, J. B. (2008). Reducing AIDS-related stigma in developing countries: The importance of theory- and evidence-based interventions. Psychology, Health \& Medicine, 13(4), 450-460. https://doi.org/10.1080/13548500701687171

Brandt, C., Zvolensky, M. J., Woods, S. P., Gonzalez, A., Safren, S. A., \& O'Cleirigh, C. M. (2017). Anxiety symptoms and disorders among adults living with HIV and AIDS: A critical review and integrative synthesis of the empirical literature. Clinical Psychology Review, 51, 164-184. https://doi.org/10.1016/j.cpr.2016.11.005

Brent, R. J. (2016). The value of reducing HIV stigma. Social Science \& Medicine, 151, $233-240$. https://doi.org/10.1016/j.socscimed.2016.01.014

Chambers, L. A., Rueda, S., Baker, D. N., Wilson, M. G., Deutsch, R., Raeifar, E., Rourke, S. B., \& the Stigma Review Team. (2015). Stigma, HIV and health: A qualitative synthesis. BioMed Central Public Health, 15(848), 1-17. https://doi.org/10.1186/s12889-015-2197-0

Chibanda, D., Benjamin, L., Weiss, H. A., \& Abas, M. (2014). Mental, neurological, and substance use disorders in people living with HIV/AIDS in low-and middle-income countries. Journal of Acquired Immune Deficiency Syndromes, 67(1), S54-67. https://doi.org/10.1097/QAI.0000000000000258

Dabaghzadeh, F., Jabbari, F., Khalili, H., \& Abbasian, L. (2015). Associated factors of suicidal thoughts in HIV-positive individuals. Iranian Journal of Psychiatry, 10(3), 185-191. https://doi.org/10.2217/fvl.14.107

Demmer, C. (2011). Experiences of families caring for an HIV-infected child in KwaZulu-Natal, South Africa: An exploratory study. AIDS Care, 22(3), 1-7. https://doi.org/10.1080/09540121.2010.542123

dos Santos, M. M. L., Kruger, P., Mellors, S. E., Wolvaardt, G., \& van der Ryst, E. (2014). An exploratory survey measuring stigma and discrimination experienced by people living with HIV/AIDS in South Africa: The people living with HIV stigma index. BioMed Central Public Health, 14(80), 1471-2458. https://doi.org/10.1186/1471-2458-14-80

Durvasula, R., \& Miller, T. M. (2014). Substance abuse treatment in persons with HIV/AIDS: Challenges in managing triple diagnosis. Behavioural Medicine, 40, 43-52. https://doi.org/10.1080/08964289.2013.866540

Goffman, E. (1963). Notes on the management of spoiled identity. Englewood Cliffs: Prentice-Hall.

Goldberg, D. P. (1972). The detection of psychiatric illness by questionnaire: A technique for the identification and assessment of non-psychotic psychiatric illness. London: Oxford University Press.

Idemudia, E. S., \& Matamela, N. A. (2012). The role of stigmas in mental health: A comparative study. Curationis, 35(1), 1-8. https://doi.org/10.4102/curationis.v35i1.30

Maughan-Brown, B. (2010). Stigma rises despite antiretroviral roll-out: A longitudinal analysis in South Africa. Social Science \& Medicine, 70, 368-374. https://doi.org/10.1016/j.socscimed.2009.09.041

Niu, L., Luo, D., Liu, Y., Silenzio, V. M. B., \& Xiao, S. (2016). The mental health of people living with HIV in China, 1998-2014: A systematic review. PLoS ONE, 11(4), 1-18. https://doi.org/10.1371/journal.pone.0153489

Onyebuchi-Iwudibia, O., \& Brown, A. (2014). HIV and depression in Eastern Nigeria: The role of HIV-related stigma. AIDS Care, 26(5), 653- 657. https://doi.org/10.1080/09540121.2013.844761

Rael, C. T., \& Hampanda, K. (2016). Understanding internalized HIV/AIDS-related stigmas in the Dominican Republic: A short report. AIDS Care, 28(3), 319-324. https://doi.org/10.1080/09540121.2015.1095277

Senyalo, R. G., Maja, T., \& Ramukumba, T. S. (2015). Stigma experienced by people living with HIV and AIDS in Soshanguve, South Africa. African Journal for Physical, Health Education, Recreation and Dance (AJPHERD), 21, 94-106.

Sherr, L., Clucas, C., Harding, R., Sibley, E., \& Catalan, J. (2011). HIV and depression: A systematic review of 
interventions. Psychology, Health \& Medicine, 16, 493- 527. https://doi.org/10.1080/13548506.2011.579990

Sikkema, K. L., Dennis, A. C., Watt, M. H., Choi1, K. W., Yemeke, T. T., \& Joska, J. A. (2015). Improving mental health among people living with HIV: A review of intervention trials in low- and middle-income countries. Glob Ment Health Camb, 2, 1-28. https://doi.org/10.1017/gmh.2015.17

Statistics South Africa. (2013). Living Conditions Survey: Poverty Profile of South Africa; Application of the poverty lines on the LCS. Accessed on 25th August 2016 from http://www.statssa.gov.za/publications/P0310/P03102013.pdf

Uthman, O. A., Magidson, J. F., Safren, S. A., \& Nachega, J. B. (2014). Depression and adherence to antiretroviral therapy in low-middle-and high-income countries: A systematic review and meta-analysis. Current HIV/AIDS Reports, 11, 291-307. https://doi.org/10.1007/s11904-014-0220-1

Uys, L., Chirwa, M., Kohi, T., Greeff, M., Naidoo, J., Makoae, L., . . Holzemer, W. L. (2009). Evaluation of a health setting-based stigma intervention in five African countries. AIDS Patient Care and STDs, 23(12), 1059-1066. https://doi.org/10.1089/apc.2009.0085

Westbrook, L. E., \& Bauman, L. J. (1996). Perceived stigma of HIV/AIDS scale. New York: Bronx.

Yalom, L. D. (1995). The theory and practice of group psychotherapy (4th ed). New York: Basic Books.

Yi, S., Chhoun, P., Suong, S., Thin, K., Brody, C., \& Tuot, S. (2015). AIDS-related stigma and mental disorders among people living with HIV: A cross-sectional study in Cambodia. PLoS ONE, 10(3), 1-16. https://doi.org/10.1371/journal.pone.0121461

Yu, N. X., Zhang, J., \& Chan, C. L. W. (2016). Health care neglect, perceived discrimination, and dignity-related distress among Chinese patients with HIV. AIDS Education and Prevention, 28(1), 90-102. https://doi.org/10.1521/aeap.2016.28.1.90

\section{Copyrights}

Copyright for this article is retained by the author(s), with first publication rights granted to the journal.

This is an open-access article distributed under the terms and conditions of the Creative Commons Attribution license (http://creativecommons.org/licenses/by/4.0/). 